\title{
Duration of action of sodium cromoglycate on exercise induced asthma: comparison of 2 formulations
}

\author{
E BAR-YISHAY, I GUR, M LEVY, D VOLOZNI, AND S GODFREY \\ Pulmonary Function Laboratory and Department of Pediatrics, Hadassah University Hospital, Israel
}

SUMmARY Thirteen asthmatic children aged 9-14 years participated in a double blind randomised trial to compare the effectiveness and duration of action of 2 formulations of sodium cromoglycate; one a $20 \mathrm{mg}$ capsule of powdered sodium cromoglycate delivered by turbo inhaler (spinhaler), and the other $1 \mathrm{mg}$ of aerosolised sodium cromoglycate delivered by pressurised cannister inhaler (aerosol). The children performed exercise tests on each of 3 days in a 10 day period-15 minutes, 2 hours, and 6 hours after inhalation of powder, aerosol, or a placebo. Two patients were not protected from exercise induced asthma by either formulation of sodium cromoglycate. Among the remaining patients both formulations gave good protection from exercise induced asthma 15 minutes after inhalation, and the effect of both wore off steadily over the next 6 hours. The spinhaler gave appreciably better protection than the aerosol at 15 minutes after inhalation, and was the only formulation to provide good protection at 2 hours and 6 hours. The more limited effectiveness of the aerosol may be explained by the lower dose of sodium cromoglycate and the more complicated inhalation technique required.

The drug sodium cromoglycate (SCG) is known to protect most asthmatic children against clinical, antigen induced, and exercise induced asthma (EIA $)^{1-3}$ and the duration of this protection has been shown to last up to 6 hours or more. ${ }^{45} \mathrm{~A}$ new formulation of SCG has been introduced comprising $1 \mathrm{mg}$ aerosolised SCG delivered by a pressurised cannister inhaler (aerosol). We compared the protective effect and the duration of action of this formulation with that of the original formulation of $20 \mathrm{mg}$ powdered SCG delivered by turbo inhaler (spinhaler). ${ }^{6} 7$

\section{Patients and methods}

Thirteen asthmatic children aged 9-14 years participated in the double blind randomised trial and their anthropometric data and usual treatment are presented in Table 1. They attended the Pulmcnary function laboratory on 3 occasions over 10 days. On each occasion they inhaled 1 of 3 preparations; CSG aerosol, CSG spinhaler, or placebo and then performed 3 identical exercise tests 15 minutes, 2 hours and 6 hours afterwards. One patient performed only 1 exercise test on each day 15 minutes after drug inhalation and 2 patients performed only the 15 minute and 6 hour tests. Their results have been included where appropriate. In addition, 5 of
13 patients performed an exercise test 4 hours after treatment. Two placebos were used, one identical in format to the spinhaler and the other to the aerosol. The patients inhaled both a spinhaler and an aerosol before the first exercise test, one an active preparation and the other a placebo, except on the placebo day when both preparations were placebos.

The exercise consisted of 6 minutes of cycling on a cycle ergometer (Lode Inst, $\mathrm{N} \mathrm{V}$ ) at a fixed load in such a manner as to achieve $60 \%$ of maximum predicted oxygen consumption. ${ }^{8}$ Once set this load was kept constant throughout the study for each

Table 1 Details of patients

\begin{tabular}{llllll}
\hline Case No & Sex & $\begin{array}{l}\text { Age } \\
(y r)\end{array}$ & $\begin{array}{l}\text { Height } \\
(\mathrm{cm})\end{array}$ & $\begin{array}{l}\text { Weight } \\
(\mathrm{kg})\end{array}$ & $\begin{array}{l}\text { Usual } \\
\text { treatment }\end{array}$ \\
\hline 1 & M & 11 & 139 & 31 & ISB \\
2 & $\mathrm{~F}$ & 9 & 136 & 33 & ISB \\
3 & $\mathrm{M}$ & 9 & 138 & 30 & ISB \\
4 & $\mathrm{~F}$ & 12 & 152 & 46 & ISB \\
5 & $\mathrm{M}$ & 10 & 137 & 30 & ISB, HDT \\
6 & $\mathrm{M}$ & 12 & 145 & 30 & ISB \\
7 & $\mathrm{~F}$ & 13 & 147 & 41 & ISB, HDT \\
8 & $\mathrm{M}$ & 12 & 140 & 32 & ISB \\
9 & $\mathrm{~F}$ & 14 & 151 & 39 & ISB \\
10 & $\mathrm{M}$ & 12 & 135 & 27 & ISB \\
11 & $\mathrm{M}$ & 13 & 149 & 30 & ISB, SCG \\
12 & $\mathrm{M}$ & 12 & 147 & 40 & ISB \\
13 & $\mathrm{M}$ & 14 & 145 & 35 & ISB, ICS \\
\hline
\end{tabular}

ISB = intermittent sympathomimetic bronchodilator; HDT $=$ high dose theophylline; $S C G=$ sodium cromoglycate; $I C S=$ inhaled corticosteroid. 
individual. To keep all exercise tests identical the patients breathed cold $\left(6 \cdot 6^{\circ} \mathrm{C}\right)$ and dry air from a specially designed respiratory circuit. These respired air conditions were kept constant for all tests. The patient was connected to the system and breathed this gas for 5 minutes before starting the exercise, throughout the exercise period, and afterwards until his or her forced expiratory volume (FEV) in $1 \mathrm{~s} \mathrm{had}$ passed the minimum value and returned to within $\pm 10 \%$ of the pre-exercise value.

Lung function tests were performed in triplicate and the best effort was chosen from each set. The $\mathrm{FEV}_{1}$ was measured with an electronic spirometer (Hewlett-Packard model 4730A). Measurements were made before treatment was given, at 15 minutes, (that is just before beginning the first exercise run), and at intervals after the completion of exercise. The same protocol was followed during the next 3 or 4 exercise tests performed each day. All measurements were performed with the patients seated on the cycle ergometer. The severity of EIA was calculated as the maximum percentage fall in $\mathrm{FEV}_{1}$ after exercise $\left(\wedge \mathrm{FEV}_{1}(\%)\right)$ :

$$
\wedge \mathrm{FEV}_{1}(\%)=\frac{\begin{array}{c}
\text { pre-exercise } \mathrm{FEV}_{1}-\text { minimum } \\
\text { post-exercise } \mathrm{FEV}_{1}
\end{array}}{\text { pre-exercise } \mathrm{FEV}_{1}} \times 100
$$

Table 2 Individual baseline forced expiratory volume values before exercise and after the 3 treatments

\begin{tabular}{lllllll}
\hline $\begin{array}{l}\text { No } \\
\text { Case }\end{array}$ & $15 \mathrm{~min}$ & $2 \mathrm{hr}$ & $4 \mathrm{hr}$ & $6 \mathrm{hr}$ & Mean & $\begin{array}{l}\% \text { of } \\
\text { predicted } \\
\text { normal }\end{array}$ \\
\hline 1 & 1.67 & 1.56 & & 1.60 & 1.61 & 78 \\
2 & 1.60 & 1.65 & & 1.50 & 1.58 & 93 \\
3 & 1.64 & 1.50 & & 1.60 & 1.58 & 81 \\
4 & 2.15 & 2.12 & & 1.74 & 2.01 & 84 \\
5 & 1.70 & 1.69 & & 1.42 & 1.55 & 81 \\
6 & 2.18 & 2.09 & & 2.06 & 2.11 & 89 \\
7 & 2.32 & 2.34 & & 2.33 & 2.32 & 98 \\
8 & 1.57 & & & & 1.57 & 74 \\
9 & 2.03 & 2.06 & 2.08 & 2.00 & 2.05 & 82 \\
10 & 1.36 & 1.42 & 1.41 & 1.40 & 1.40 & 69 \\
11 & 1.76 & 1.78 & 1.76 & 1.78 & 1.78 & 67 \\
12 & 1.85 & 1.78 & 1.87 & 1.81 & 1.84 & 74 \\
13 & 1.69 & 1.98 & 1.95 & 1.89 & 1.89 & 77 \\
\hline Mean & 1.81 & 1.83 & 1.81 & 1.76 & 1.79 & 80.5 \\
SEM & 0.08 & 0.08 & 0.11 & 0.08 & 0.08 & 2.5 \\
\hline
\end{tabular}

where the pre-exercise value was that measured immediately before starting exercise while breathing the test gas.

Statistical comparisons were made between either drug and placebo or drug and drug tests by means of student's paired $t$ test and the SEM given in the text refers to these comparisons. One way analysis of variance ${ }^{9}$ was used to compare baseline lung function between different types of test, and differences were considered significant where $\mathbf{P}<0.05$.

\section{Results}

Table 2 gives individual baseline $\mathrm{FEV}_{1}$ values for each exercise test after each of the 3 treatments and the mean values of the various exercise parameters are in Table 3. There were no significant differences between any of these parameters in the tests.

The $\wedge F E V_{1}(\%)$ for each patient in each of the tests is given for each treatment (Table 4). EIA was significantly attenuated at 15 minutes after preexercise treatment with either aerosol or spinhaler compared with placebo $\left(\Lambda \mathrm{FEV}_{1}\right.$, mean $(\mathrm{SEM})=17$ ( $2 \%$ ) (aerosol), 12 (4\%) (spinhaler), and $25(4 \%)$ (placebo); $\mathbf{P}<0.05$ for each drug compared with placebo). Only the spinhaler treatment was still effective after 2 hours in protecting the patients against EIA. Analysis of the data available on the 5 patients who exercised 4 hours after treatment is limited because of the small group size. When exercise was performed 6 hours after treatment there was no appreciable protection by the aerosol but the spinhaler treatment gave a significantly better protection than either aerosol or placebo $\left(\Lambda \mathrm{FEV}_{1} \%\right.$, mean (SD) $=24$ (5), 33 (3), and 31 (5); $P<0.05$ for each comparison).

Two of the patients (cases 1 and 9) were not protected in any test by either formulation of SCG and indeed the patient in case 9 suffered greater EIA after the drug than after the placebo. Since these 2 patients were unprotected their results could not be used to evaluate the duration of protection in the majority group of 11 patients. The results were therefore recalculated for these 11 patients alone and

\begin{tabular}{|c|c|c|c|c|c|c|c|c|c|c|c|c|}
\hline & \multicolumn{4}{|c|}{ Spinhaler } & \multicolumn{4}{|l|}{ Placebo } & \multicolumn{4}{|l|}{ Aerosol } \\
\hline & $15 \mathrm{~min}$ & $2 h r$ & $4 h r$ & $6 h r$ & $15 \mathrm{~min}$ & $2 h r$ & $4 h r$ & $6 h r$ & $15 \mathrm{~min}$ & $2 h r$ & $4 h r$ & $6 h r$ \\
\hline $\begin{array}{l}\text { Ventilation } \\
\text { (1/minute) }\end{array}$ & $\begin{array}{l}47 \cdot 0 \\
(3 \cdot 4)\end{array}$ & $\begin{array}{l}44 \cdot 0 \\
(2 \cdot 7)\end{array}$ & $\begin{array}{l}43 \cdot 0 \\
(3 \cdot 6)\end{array}$ & $\begin{array}{l}43 \cdot 0 \\
(3 \cdot 4)\end{array}$ & $\begin{array}{l}49 \cdot 0 \\
(2 \cdot 6)\end{array}$ & $\begin{array}{l}45 \cdot 0 \\
(2 \cdot 5)\end{array}$ & $\begin{array}{l}48 \cdot 0 \\
(6 \cdot 6)\end{array}$ & $\begin{array}{l}47 \cdot 0 \\
(2 \cdot 7)\end{array}$ & $\begin{array}{l}46 \cdot 0 \\
(2 \cdot 1)\end{array}$ & $\begin{array}{l}50 \cdot 0 \\
(3 \cdot 6)\end{array}$ & $\begin{array}{l}47 \cdot 0 \\
(4 \cdot 8)\end{array}$ & $\begin{array}{l}46 \cdot 0 \\
(3 \cdot 9)\end{array}$ \\
\hline $\begin{array}{l}\text { Oxygen consumption } \\
\text { (ml/minute) }\end{array}$ & $\begin{array}{l}1205 \\
(85 \cdot 2)\end{array}$ & $\begin{array}{l}1205 \\
(85 \cdot 6)\end{array}$ & $\begin{array}{l}1272 \\
(104 \cdot 3)\end{array}$ & $\begin{array}{l}1193 \\
(82)\end{array}$ & $\begin{array}{l}1263 \\
(56 \cdot 4)\end{array}$ & $\begin{array}{l}1257 \\
(102)\end{array}$ & $\begin{array}{l}1282 \\
(116)\end{array}$ & $\begin{array}{l}1310 \\
(107)\end{array}$ & $\begin{array}{l}1265 \\
(87)\end{array}$ & $\begin{array}{l}1331 \\
(86)\end{array}$ & $\begin{array}{l}1429 \\
(155 \cdot 5)\end{array}$ & $\begin{array}{l}1384 \\
(115 \cdot 4)\end{array}$ \\
\hline $\begin{array}{l}\text { Heart rate } \\
\quad(\text { per minute })\end{array}$ & $\begin{array}{l}174 \\
(6 \cdot 0)\end{array}$ & $\begin{array}{l}180 \\
(4 \cdot 0)\end{array}$ & $\begin{array}{l}178 \\
(5 \cdot 0)\end{array}$ & $\begin{array}{l}168 \\
(5 \cdot 0)\end{array}$ & $\begin{array}{l}173 \\
(5 \cdot 0)\end{array}$ & $\begin{array}{l}174 \\
(5 \cdot 0)\end{array}$ & $\begin{array}{l}179 \\
(4 \cdot 0)\end{array}$ & $\begin{array}{l}177 \\
(3 \cdot 0)\end{array}$ & $\begin{array}{l}174 \\
(3 \cdot 0)\end{array}$ & $\begin{array}{l}176 \\
(5 \cdot 0)\end{array}$ & $\begin{array}{l}174 \\
(3 \cdot 0)\end{array}$ & $\begin{array}{l}171 \\
(4 \cdot 0)\end{array}$ \\
\hline
\end{tabular}
are summarised in the Figure. There were 11 studies

Table 3 Mean value (SEM) of various exercise parameters after inhalation of spinhaler, placebo, and aerosol 
Table 4 Individual postexercise falls in forced expiratory volume (\%) after placebo $(P)$, aerosol $(A)$, and spinhaler $(S)$

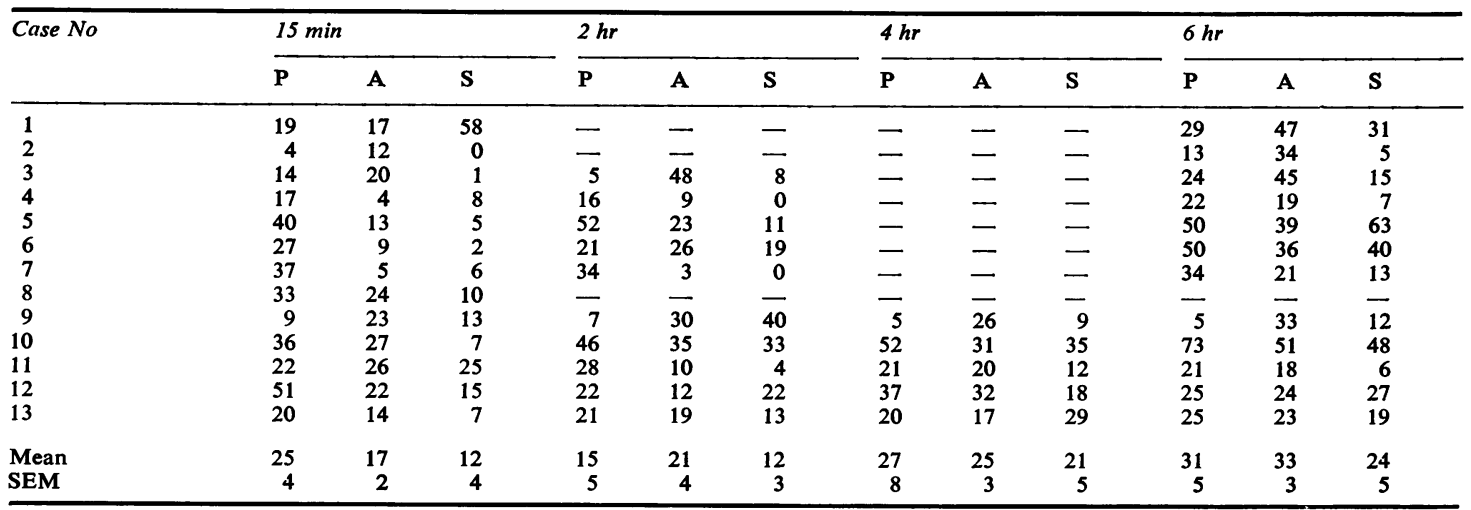

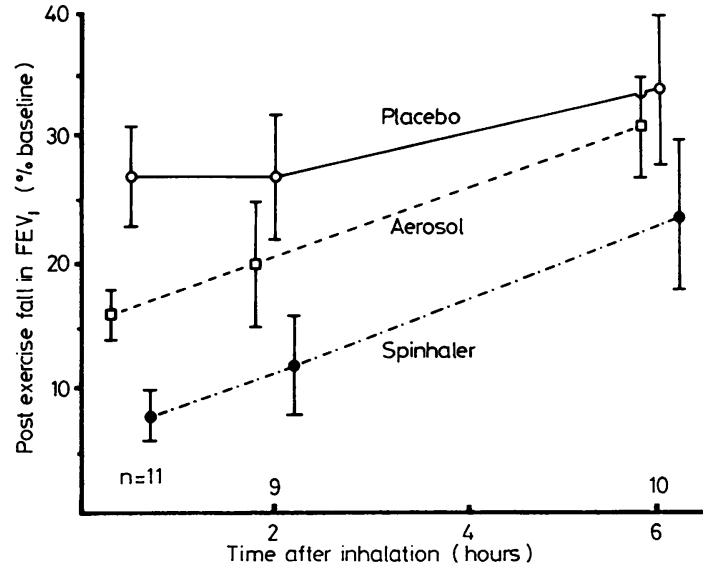

Figure Mean (SE) postexercise fall in forced expiratory volume (FEV) expressed as per cent baseline in the placebo and drug studies for the 11 subjects protected by sodium cromoglycate. The number of patients tested at each time after the medication is given.

at 15 minutes, 9 at 2 hours, and 10 at 6 hours. As there were only 4 studies at 4 hours these have been omitted. Analysis in the protected group showed appreciably less EIA at all 3 times after inhalation for the spinhaler compared with placebo but only at the 15 minute test for the aerosol. As can be seen from the Figure, the protection given by the spinhaler was greater than that by the aerosol at all times, but the difference between them was significant only at 15 minutes and 2 hours and protection wore off steadily over the 6 hour period.

\section{Discussion}

This controlled study aimed at comparing the relative effectiveness and duration of action of 2 formulations of SCG and a placebo. The results showed that both formulations were effective in protecting most young asthmatics from EIA when given just before exercise. These results agree with those of Silverman and Andrea ${ }^{3}$ and of Anderson et al. $^{4}$ in their investigation of the SCG spinhaler formulation. The results further indicated that protection can last up to 6 hours and that in most patients the spinhaler was more effective than the aerosol treatment. SCG in powder form has already been shown to have a similar duration of action in protecting against EIA $^{4}$ and against allergen challenge. ${ }^{5}$

The method for evaluating the effectiveness and duration of the 3 treatments was that of serial exercise tests at intervals after inhalation as described by Silverman et al. ${ }^{10}$ The mean baseline pre-exercise FEV $_{1}$ values were $80 \%$ of that predicted for the whole group and there were no appreciable differences in baseline lung function between either the individual drug formulations or between the individual time intervals that could have biased the results. In the light of new findings on the relative importance of airway cooling by respiratory heat loss ${ }^{11}$ we added the regulation of inspired air conditions to the method of Silverman et al..$^{10}$

The aerosol formulation of SCG has already been proved an effective preventive drug both clinically and in laboratory studies. ${ }^{67}$ The only study of its protection against EIA $^{12}$ was performed while the patients exercised immediately after drug administration, and it compared only the effect of the new formulation to that of placebo. We know of no published reports that compare the protection and duration of action of the new formulation of SCG to that of the powdered spinhaler preparation in EIA. Although the somewhat better protection of the spinhaler treatment may be because the dose used 
was 10 times that of the aerosol formulation, this difference is probably an overestimate since only a small proportion of the powder is in particles small enough to penetrate the airways. ${ }^{13}$

We believe that our results show that both formulations of SCG can protect children against EIA if taken shortly before exercise. The subsequent better duration of protection by the older spinhaler formulation is probably due to the simpler inhalation technique, which is more suitable for children or patients who have not perfected the technique for inhaling a pressure packed aerosol.

\section{References}

1 Howell JBL, Altounyan REC. A double blind trial of disodium cromoglycate in the treatment of allergic bronchial asthma. Lancet 1967 ; ii: 539-42.

2 Pepys J, Hargreave FE, Chan M, McCarthy DS. Inhibitory effects of disodium cromoglycate on allergeninhalation tests. Lancet 1968; ii: 134-7.

3 Silverman M, Andrea T. Time course of effect of disodium cromoglycate on exercise-induced asthma. Arch Dis Child 1972; 47: 419-22.

4 Anderson SD. Silverman M, Konig P, Godfrey S, Exercise-induced asthma. Br J Dis Chest 1975; 69: 1-19.

5 Kolotkin BM, Lee CK, Townley RG. Duration and specificity of sodium cromolyn on allergen inhalation challenges in asthmatics. J Allergy Clin Immunol 1974; 53: 288-97.
${ }^{6}$ So SY, Yu DYC. Sodium cromoglycate delivered by pressurized aerosol in the treatment of asthma. Clin Allergy 1981 ; 11 : 479-82.

7 Robson RA, Taylor BJ, Taylor B. Sodium cromoglycate: spincaps or metered dose aerosol. Br J Clin Pharmacol $1981 ; 11$ : 383-4.

8 Godfrey S. Exercise Testing in Children. Applications in Health and Disease. London: W. B. Saunders, 1974.

- Snedecor GW, Cochran WG. Statistical Methods. 6th ed. Iowa: Iowa State University Press, 1967.

10 Silverman M, Konig P, Godfrey S. The use of serial exercise tests to assess the efficacy and duration of action of drugs for asthma. Thorax $1973 ; 28$ : 574-8.

1 Deal EC, Jr, McFadden ER, Jr, Ingram $\mathrm{RH}, \mathrm{Jr}$, Strauss RH, Jaeger JJ. Role of respiratory heat exchange in production of exercise induced asthma. J Appl Physiol 1979; 46: 467-75.

12 Sanguinetti CM, Gasparini S, Bonifazi F, Vennarucci LS. Exercise-induced asthma: diagnosis and prevention with a metered dose aerosol formulation of sodium cromoglycate. Respiration 1982; 43: 132-41.

13 Godfrey S, Zeidifard E, Brown K, Bell JH. The possible site of action of sodium cromoglycate assessed by exercise challenge. Clin Sci Mol Med 1974; 46: 265-72.

Correspondence to Professor Simon Godfrey, Department of Paediatrics, Hadassah University Hospital, Mount Scopus, Jerusalem, Israel.

Received 3 May 1983. 